\title{
Patients' Perceptions of Cholesterol, Cardiovascular Disease Risk, and Risk Communication Strategies
}

Roberta E. Goldman, PbD ${ }^{1,2}$

Donna R. Parker, ScD $D^{1,2}$

Charles B. Eaton, $M D^{1,2}$

Jeffrey M. Borkan, $M D, P b D^{1,2}$

Robert Gramling, $M D^{1,2}$

Rebecca T. Cover, $\mathrm{BA}^{2,3}$

David K. Abern, PbD

'Department of Family Medicine, Brown Medical School, Providence, RI

${ }^{2}$ Center for Primary Care and Prevention, Brown Medical School/Memorial Hospital of Rhode Island, Pawtucket, RI

${ }^{3}$ University of California, Berkeley, Berkeley, Calif

${ }^{4}$ Abacus Management Technologies, LLC, Cranston, RI,

${ }^{5}$ Health e-Technologies Initiative, Brigham and Women's Hospital/Harvard Medical School, Boston, Mass

AC Annals Journal Club selectionsee inside back cover.

Conflicts of interest: none reported

\section{CORRESPONDING AUTHOR}

Roberta E. Goldman, PhD Department of Family Medicine Brown Medical School Center for Primary Care and Prevention Memorial Hospital of Rhode Island 111 Brewster Street

Pawtucket, RI 02860

roberta_goldman@mhri.org

\begin{abstract}
PURPOSE Despite some recent improvement in knowledge about cholesterol in the United States, patient adherence to cholesterol treatment recommendations remains suboptimal. We undertook a qualitative study that explored patients' perceptions of cholesterol and cardiovascular disease (CVD) risk and their reactions to 3 strategies for communicating CVD risk.

METHODS We conducted 7 focus groups in New England using open-ended questions and visual risk communication prompts. The multidisciplinary study team performed qualitative content analysis through immersion/crystallization processes and analyzing coded reports using NVivo qualitative coding software.

RESULTS All participants were aware that "high cholesterol" levels adversely affect health. Many had, however, inadequate knowledge about hypercholesterolemia and CVD risk, and few knew their cholesterol numbers. Many assumed they had been tested and their cholesterol concentrations were healthy, even if their physicians had not mentioned it. Standard visual representations showing statistical probabilities of risk were assessed as confusing and uninspiring. A strategy that provides a cardiovascular risk-adjusted age was evaluated as clear, memorable, relevant, and potentially capable of motivating people to make healthful changes. A few participants in each focus group were concerned that a cardiovascular riskadjusted age that was greater than chronological age would frighten patients.
\end{abstract}

CONCLUSIONS Complex explanations about cholesterol and CVD risk appear to be insufficient for motivating behavior change. A cardiovascular risk-adjusted age calculator is one strategy that may engage patients in recognizing their CVD risk and, when accompanied by information about risk reduction, may be helpful in communicating risk to patients.

Ann Fam Med 2006;4:205-212. DOI: 10.1370/afm.534.

\section{INTRODUCTION}

$\mathrm{D}$ espite recent advances in the diagnosis and treatment of cardiovascular disease (CVD), it remains the leading cause of death in the United States. ${ }^{1}$ In 1985 the National Heart, Lung, and Blood Institute launched the National Cholesterol Education Program (NCEP), which issued the Adult Treatment Panel (ATP I, II, and III) clinical guidelines aimed at reducing the burden of CVD through improved cholesterol management. ${ }^{2-4}$ The NCEP produced educational kits for clinicians and patient-oriented media programming including the "Know Your Cholesterol Numbers, Know Your Risk" campaign. 5,6

Cholesterol knowledge is reported to have improved since the 1980s, ${ }^{7,8}$ but important information gaps remain. One study reported that from 1983 to 1995, there was an increase in the percentage of Americans who had heard of high blood cholesterol levels, who had been informed of their levels, and who knew their total cholesterol number. ${ }^{9}$ From 1983 to 1995 , 
the percentage of the public who had heard of high blood cholesterol levels rose from $77 \%$ to $93 \%$, and the percentage who were told their cholesterol values rose from $21 \%$ to $65 \%$. Furthermore, the percentage who reported that they knew their level increased from $3 \%$ to $49 \% .{ }^{9}$ Other studies, however, showed that only about one third of the population reporting an elevated total cholesterol concentration or using cholesterollowering medications were aware they had hypercholesterolemia, ${ }^{10}$ and that whereas some individuals underestimate their risk of developing a disease, ${ }^{11,12}$ others overestimate risk. ${ }^{13}$ Even with some improvements in knowledge, patient acceptance of and adherence to cholesterol treatment recommendations remain suboptimal, ${ }^{9,14,15}$ as inaccurate perceptions of vulnerability to a disease can inhibit prevention behaviors. ${ }^{16-18}$

Information alone may not promote behavior change. Strategies are necessary to engage patients with how cholesterol levels relate to their CVD risk, ${ }^{19,20}$ as well as mechanisms to address the impact of low functional health literacy on understanding. ${ }^{21,22}$ Functional health literacy goes beyond written communication to include innumeracy and a person's ability to comprehend oral communication. ${ }^{23}$ Almost one half of all adults in the United States have literacy levels that impede their ability to understand health information and apply it to decision making. ${ }^{22}$ Recent studies of patient-physician communication found innumeracy to be a major barrier to use of standard bounded probabilities (ie, 0 to $1,0 \%$ to $100 \%$ ) for comprehension of risk information. ${ }^{24,25}$ One promising method for overcoming some of these barriers is to use visual displays of numerical information ${ }^{26-28}$ or to use analogies for expression of probability. ${ }^{29}$ Recent thought on low health literacy also emphasizes strategic actions within health care systems ${ }^{22}$ to ameliorate some of the consequences, ${ }^{23,30,31}$ including use of new strategies for patient education.

As part of a project to enhance implementation of the ATP III guidelines in primary care practice, we conducted exploratory, qualitative research about patients' perceptions of cholesterol, CVD risk, and risk communication strategies. We report findings from that study in this article.

\section{METHODS}

\section{Study Design, Participants, and Data Collection}

The authors were part of a multidisciplinary group of primary care researchers with different theoretical groundings and distinct methodological perspectives: an anthropologist (REG), an epidemiologist (DP), a family physician/anthropologist (JB), 2 family physicians (CE, RG), a research assistant (RC), and a behavioral psychologist with a specialty in e-Health (DA). This group included both predominately qualitative (REG, JB) and predominantly quantitative (CE, DP, DA, RG) researchers, as well as a family physician who held a clear belief in the efficacy of interventions around cholesterol (CE) and one who was more skeptical (JB). We discussed these biases and preferences openly during research development, implementation, and analysis phases, and considered the potential effect on our interpretation of data.

Between January and March 2003, we conducted 7 focus groups with 50 adults in the northeastern United States. ${ }^{32-34}$ We used focus groups to benefit from the interactive discussion among participants these groups foster; participants respond not only to direct questions from the moderator but also to questions and ideas posed by other participants.

Participants were recruited from primary care practices and through a newspaper advertisement calling for adults to discuss physician-patient communication. We advertised this broader aim of our study to avoid limiting recruitment to those who were especially motivated to talk about cholesterol. To meet the study inclusion criteria, the participants had to be older than 18 years and able to speak English.

The tape-recorded focus groups were held in a hospital conference room or in community locations. Before beginning each 2-hour discussion, participants signed an informed consent that was approved by the hospital's human subjects protection review board. They received $\$ 25$ in cash for their participation.

The groups were moderated by an anthropologist (REG) using a guide of open-ended questions supplemented by spontaneous probes (available online-only in the Supplemental Appendix 1 at http://annfammed. org/cgi/content/full4/3/205/DC1). The subset of topics reported in this article are knowledge and perceptions of cholesterol, perceptions of risk associated with cholesterol, and assessment of CVD risk communication methods. To compare patients' reactions to 2 standard visual risk communication strategies ${ }^{26-28}$ and HeartAge (our developing strategy for communicating cardiovascular risk-adjusted age), we evaluated their responses to 3 visual representations of risk for a 10 -year coronary heart disease event probability according to the Framingham Heart Study data. ${ }^{35}$ The NCEP published in its 2001 evidence-based consensus ATP III guidelines a prediction equation for the 10 -year coronary h eart disease risk (recognized myocardial infarction, silent myocardial infarction, coronary insufficiency, and coronary heart disease death) by evaluating the multivariate risk associated with age, sex, current cigarette smoking, total cholesterol concentration, high-density lipoprotein cholesterol concentration, and 
systolic blood pressure (treated or not treated). ${ }^{4}$ This equation is based upon the 10-year follow-up of 2,489 men and 2,856 women from the original Framingham cohort and the first cycle of the Framingham Offspring study, aged 30 to 74 years at baseline in 1971 to 1974 . This risk equation has been shown to be valid in multiple ethnic cohorts. ${ }^{36}$

For the visual displays, we presented data for a 42 year-old man with a high 10 -year risk $(0.25)$ of coronary heart disease based on the Framingham Heart Score. Participants were shown the following: (1) First they were shown a crowd chart ${ }^{27}$ depicting 100 stick figures with 25 shaded to represent the proportion expected to experience a coronary heart disease event during the next 10 years and then an identical chart with the risk for a same-aged man who had no risk factors (0.01 probability, 1 figure shaded), which visually depicted both absolute and relative risk reductions.

(2) Then they were shown a simple vertical bar graph comparing the current risk $(0.25)$ as a full column with a column to represent the risk for a same-aged man who had no risk factors (0.01), which visually depicted relative risk reduction. (3) Finally, they were shown a simple horizontal bar chart displaying cardiovascular risk-adjusted age that we called HeartAge, which had 2 bars representing ages from 0 to 76 years. The first bar represented the individual's true chronological age (42 years) and the second bar showed how this individual compared with the average age of a same-sex person in the Framingham Heart Study having the same 10year probability of experiencing a CHD event. For the demonstration case, the 42-year-old had the same risk as a 70 -year-old.

\section{Data Analysis}

The coauthors conducted preliminary analyses on an ongoing basis as each focus group transcript was completed. We recognized we were reaching data saturation when we began to hear repetitive comments, with few new data generated in the final groups. After completion of the focus groups, from May through December 2003, we met regularly to conduct an in-depth analysis using the immersion/crystallization method. ${ }^{37}$ This involved repeatedly listening to the audiotapes and reading and discussing the transcripts to identify emerging themes and salient topics. After we developed an initial codebook and clarified definitions, the transcript texts were subjected to line-by-line coding with the qualitative software NVivo. ${ }^{38}$ The codebook was modified by team consensus as the need for new codes emerged. We used the coded reports to facilitate further analysis discussions, develop links between themes, finalize data interpretation, and identify supporting quotations. Searches for alternative interpretations were conducted and discussed before final decisions were made about how to report and discuss the findings.

\section{RESULTS}

Participant characteristics are displayed in Supplemental Table 1 (available online-only at http:// annfammed.org/cgi/content/full4/3/205/DC1). Of the 7 focus groups, 2 were held in affluent communities; for 1 group we recruited from a primarily lowincome clinic, though all groups included mixed income and education levels. Participants with college or higher degrees did not always have correspondingly higher income than those with less education, though for some a lower income might have been due to being currently retired. Overall, participants were aged 27 to 84 years; household yearly income ranged from less than $\$ 10,000$ to more than $\$ 60,000$; and education ranged from high school to postgraduate and professional degrees.

\section{Knowledge and Perceptions About Cholesterol} Definitions of Cholesterol

All participants were aware that high cholesterol levels adversely affect health, though many were surprised that they only recently heard about this issue. Participants' explanations included that cholesterol is a newly discovered health problem, that the recent plethora of medication advertisements raised awareness, and that doctors only lately became concerned about cholesterol. Table 1 lists participants' perceptions about cholesterol.

There were similarities across socioeconomic

\begin{tabular}{|ll}
\hline Table 1. Participants' & Perceptions of Cholesterol \\
\hline Characteristic & Perception \\
\hline What it is & Goop \\
& Liquid \\
& Concentrated fats \\
& Saturated fats \\
Where it is & Fat in the blood \\
& Fat in your veins \\
& Fats in foods \\
What it is associated with & Steaks \\
& Pork \\
& Butter \\
& Lard \\
& Overweight \\
What puts you at risk & Fatty foods \\
& Impure foods \\
& Too little exercise \\
& Heredity \\
& Overweight \\
Clogs arteries \\
What it does & Clogs veins \\
& Causes heart attacks and strokes \\
& \\
&
\end{tabular}


groups in the ways participants described cholesterol and their confusion about what cholesterol is, though some with higher education provided more accurate descriptions and focused on the more complex aspects of cholesterol risk. For example, a man who showed a good understanding of cholesterol still wondered:

"Since I've been on the medication a while, is it maintaining status quo? My concern is it may reduce the risk factor, but what's the relationship between the residual clogging you might have and the fact that you're taking medication?"

Some participants associated cholesterol with blood pressure, variously assuming that if one is low the other will be low, that high cholesterol levels cause the same physical symptoms as high blood pressure, and that high cholesterol levels and high blood pressure cause each other. Although many used appropriate words to talk about cholesterol, not all conceptualizations of biological processes were accurate. Some spoke of levels of cholesterol (high/low), while many across groups referred to cholesterol in absolute terms. As a participant admitted, "I don't even know what it's made up of. But I know some people have it and some people don't."

\section{Desire for Information}

Many participants wanted information about cholesterol that was clear and unchanging. They were frustrated by shifting health messages regarding diet and were reluctant to believe dietary recommendations. Some purposively avoided thinking about cholesterol, whereas others simply remained uninformed. For example, a man who was currently taking cholesterol-lowering medication had not received explanations from his physician, and he consistently forgot to ask questions. He disclosed, "I don't know what it is. I don't know where it comes from. I don't know where it goes."

\section{Diet}

Many participants told stories about a sibling or friend who eats "whatever he wants" and has normal cholesterol values, whereas others who eat a healthful diet have high cholesterol values. Nevertheless, despite prevailing doubts about the accuracy of dietary recommendations, most participants acknowledged some association of diet with high cholesterol levels. Fats were frequently mentioned, and some participants in every group cited health consequences of saturated fats or the benefits of certain oils. Participants also cited food- and preparation-related factors as contributing to high cholesterol levels: chemicals in animal feed; pesticides on plants; and foods that are not fresh and natural, that are pasteurized, have preservatives, and are processed, frozen, and canned. Participants often conflated general issues about food quality and lifestyle with concerns about diet and cholesterol.

Participant 1: "This is my problem with the high cholesterol: They say fried foods, fatty foods, eggs. My grandfather lived to be 96 years old, North Carolina. He smoked, drank, and eat fried foods every day."

Participant 2: "Yeah, but the food was different in those days than it is nowadays."

Participant 1: "How is the food different? Pork, pig feet, chittlins, ham hocks, bacon."

Participant 2: "Yeah, but the foods aren't natural anymore."

Participant 3: "I would look at it another way. In our society we're sitting down. For me, I've sat down all day at my desk working, so, where your grandfather was, what did he do all day? He was outside working."

\section{Overweight and Heredity}

Many assumed that only overweight and older people are affected by cholesterol. Younger and thinner participants were surprised when others in the groups stated that anyone might have high cholesterol levels, and they found it difficult to overcome their limited view of the risk of high cholesterol levels.

"I associate high cholesterol with high weight gain, although I know very slender people can have very high cholesterol. But somehow in my mind's eye ... I associate it with being overweight."

Stories emerged about overweight people with normal cholesterol levels who have thin siblings with high cholesterol levels. Participants talked about the impact of heredity on cholesterol and their ambivalence about heredity because familial patterns are inconsistent.

"There's a possibility [high cholesterol is] genetically inherited, ... and then if they are predisposed to this, if they do not do certain controls, then their chances are they may follow their family that may have died at a young age because of cholesterol rather than cardiac infarction or even a heart attack. But maybe we can, I think we can control it."

HDL and LDL

Few participants were familiar with the terms "HDL" (high-density lipoprotein) and "LDL" (low-density lipoprotein), though many had heard of "good" and "bad" cholesterol. Although some understood that one type should be high and the other low, participants' greater familiarity with the generalized term "cholesterol" and their recognition that high (total) cholesterol levels are unhealthy resulted in confusion about cholesterol being both good and bad, with goals for high and low numbers

"Cholesterol to me has like a negative connotation 
to it, whether it's good or bad. Why didn't they just come up with another word?"

"Blood pressure should be low. Cholesterol should be low. Everything should be low."

\section{Cholesterol Numbers}

In the 2 focus groups with the most highly educated participants, almost all knew their total cholesterol number. There were a few in each of the other groups who knew their total number, and they were usually motivated by having serious cholesterol problems or a family history of high cholesterol. An additional few in each group knew that they had been tested; they could not recall the number, but they did know whether it was high or not. Only a few participants in the entire sample knew their HDL and LDL numbers, though a few in each group knew whether their levels of good and bad cholesterol were problematic.

"I don't even know my numbers. I just know it was high, and he put me on medication for it."

"I know the good is high and the bad is low. The exact numbers always escape me."

\section{Perceptions of Risk Associated With Cholesterol} Cholesterol Numbers and CVD Risk Perceptions

Throughout the focus groups, participants claimed that cholesterol numbers were not an effective means to understand their risk for CVD and indicated that they did not personally relate to the abstractions that the cholesterol numbers represented. None of the participants recognized the NCEP slogan, "Know your cholesterol numbers; know your risk," and none found it compelling.

The level of risk that participants ascribed to high cholesterol varied, with some viewing it as a serious disease in itself, and others considering it a contributor to disease. Some prioritized taking blood pressure medication over cholesterol-lowering medication. Most viewed high cholesterol levels as less serious than high blood pressure because of the views that cholesterol can be managed while blood pressure cannot, blood pressure leads more directly to a heart attack, they have known about high blood pressure for longer, and they continue to hear more from physicians about blood pressure. Participants reasoned:

"Cholesterol doesn't kill like blood pressure."

"They don't make it an issue like they do heart disease. Cholesterol, I would say, is down on the bottom of the totem pole as far as most people are concerned of it being a high-risk factor that could kill you."

\section{Cholesterol Testing}

Participants assumed that doctors regularly test cholesterol as part of a complete physical examination even if patients are not aware that it is being done. This belief was especially strong among individuals whose physicians had ordered blood tests. Even though their physicians never spoke with them about cholesterol, nor informed them of their numbers, they assumed that their cholesterol level was normal:

"I never asked, so maybe they are testing my cholesterol. They just told me if there was anything wrong, they would let me know."

\section{Response to 3 Risk Communication Visuals}

The crowd chart was disliked by all participants. Many found the crowd chart confusing, and even those who understood the message assessed the presentation as unconvincing. Typical evaluations of the crowd chart were "busy," "your mind starts to lose the comprehension of the dots," "it doesn't have any oomph," and that it took a lot of thought to understand. The traditional bar graph showing the relative probability was viewed by most as lacking impact, "too dry," "too statistical," geared toward "scientific medical-types," and removed from personal experience. A few participants who were comfortable with statistics viewed the chart as a reasonable way to present risk information.

The third presentation, based on cardiovascular risk-adjusted age, was assessed by almost all participants as engaging and memorable. Reactions included "it's catchy," "it grabs you," "it's an eye-opener," "it's a wake-up call," and "it raises your consciousness." A few participants in each focus group, however, warned that patients might become alarmed if their calculated risk of a heart attack or dying of heart disease is similar to that of an older person. These statements generated considerable discussion among the participants. Some supported the idea that the message is simply frightening, and others countered that it is nevertheless important for people to have this information and that it may motivate them to change their behaviors. Some suggested that the cardiovascular risk-adjusted age strategy would be most useful and least alarming if it was accompanied by information about reducing one's risk for CVD. A few participants were skeptical about the validity of the age calculations and wanted more information about the variables used in the underlying formula.

Even among those who expressed concerns, participants found the concept of cardiovascular risk-adjusted age to be more engaging than the percentages provided by probability and relative risk reduction charts. They believed that remembering an age number would be easier than remembering cholesterol levels or percentages, and they were more likely to remember the calculated age changes from year to year. Some believed that the information about risk akin to an 
older person would be motivating enough to consider life changes to improve their cholesterol numbers and heart health. Table 2 includes participants' reactions to the cardiovascular risk-adjusted age strategy that exemplified many responses.

\section{DISCUSSION}

Common themes throughout all the focus groups involved participants' inadequate knowledge and awareness about cholesterol and its association with CVD risk. Participants expressed surprise that they knew so little about cholesterol and that they may never have been tested. These results are consistent with recent findings that two thirds of patients younger than 40 years, as well as one half of the Hispanic and African American patients surveyed, reported never having received a cholesterol screen-

\section{Table 2. Participants' Representative Reactions to a Strategy for Communicating Cardiovascular Risk-Adjusted Age}

\section{Concerns}

You've got to look at other things that most people won't look at. Is this clinical information, or is this statistical information? Have they actually ran these people through a series of physical tests to come up with these numbers? Or are they just drawing these numbers from medical records?

But you know, you've got to keep in mind that it may not be accurate. So you could be reading something on there. And when you walk in to see your physician, he can tell you something a little different. Something like that would make the person probably be concerned. So when he walks in there, now his blood pressure is up. I'm concerned about the numbers that this computer is going to show you which may not be accurate. It might give you a heart attack. You know.

I'm thinking that it's kind of overwhelming. It's intimidating for a man to come in who is 52 and find out he's got a heart age of 79. I think it's gonna be very upsetting. He's gonna be really shaken.

Participant 1: It's like he has one foot in the grave.

Participant 2: Because he's 50 years old. And you're saying his heart age is 72 . You know? That's ... he's almost done with life.

Participant 3: It is definitely scary. He needs to discuss the problem with his doctor immediately.

I think it's going to be startling to a lot of people. A lot of people will say, yeah, I'm 52; I feel like I'm 60. But when people see figures on a computer that's supposed to be accurate, they're going to say I'm 52, and I've got a heart of a 72 year old man, I think they're going to be in shock. Nobody wants to hear the truth.

Participant 1: So maybe you need a transition slide that says how can I improve this or what can I do.

Participant 2: So they don't walk away quaking.

\section{Benefits}

That [cardiovascular risk-adjusted age strategy] is easy, I can understand that. Yeah, that spells everything out. You can go to the doctor a year later, and boom [see how the calculated age has changed].

No, you ain't gonna forget that [the age]. Those numbers [actual age and cardiovascular riskadjusted age] are a hell of a lot easier than the first 3 you plugged in there, the HDL, whatever the heck that is.

I think the idea of [cardiovascular risk-adjusted age] made it personal. Because this is your age. It brought you into it. The other [probability estimate bar chart], I mean, that's just another graph. It's too statistical.

I think the point is to wake up. I don't think anyone's gonna pass out from seeing that [cardiovascular risk-adjusted age]. If something is wrong you need to change the way you're living.

I think the average person looking at that [cardiovascular risk-adjusted age] is going to get depressed. And after they get depressed, they're probably going to reevaluate their life. I mean that's very revealing.

Your [cardiovascular risk-adjusted age] is telling you there's something medically going on. And you need to make some more changes. ing recommendation from their physicians. ${ }^{39,40} \mathrm{~A}$ low rate of screening recommendations generally may be reinforcing the perception among our participants that their cholesterol levels had been measured as part of regular physical examinations, even if their physicians cholesterol, though their descriptions of biological processes and CVD risk often contained inaccuracies. Participants with the highest education more completely described what cholesterol is and how it creates risk for heart attack and stroke, though some confusion remained. While one study found that from 1986 to 1995 the percentage of persons who knew that a desirable total cholesterol level is less than $200 \mathrm{mg} / \mathrm{dL}$ increased dramatically, ${ }_{1}^{9}$ other studies support our findings that only a small portion of patients know their own despite being generally knowledgeable about the health risks of high cholesterol. ${ }^{41}$

Giving patients more medical information may not mitigate the influence that prevailing beliefs have on patients' views of medical issues. ${ }^{14,43-45}$ Furthermore, the trend in cholesterol education toward increasingly complex explanations (that include total, HDL, LDL, triglycerides, and non-HDL cholesterol) may not lead to optimal understanding of cholesterol and may, at the same time, be insufficiently motivating for patients to work with their physicians to reduce cholesterolrelated CVD risk. Similarly, the "Know Your Cholesterol Numbers; Know Your Risk" ${ }^{16,9}$ campaign may also be suboptimal, as most participants in our study did not know their cholesterol numbers and, possibly more importantly, did not think knowing their numbers would motivate them to personalize their risk profile and engage in behavior change.

Results of this study are limited by the small geographic area from which participants were recruited. In addition, it is not possible with focus groups to obtain the detailed accounts of participants' perspectives that 
result from individual interviews. We did, however, choose to use focus groups to benefit from the interactive discussion.

To engage patients' focus on cholesterol-related CVD risk and facilitate meaningful communication with physicians, ${ }^{14}$ cholesterol education tools must be able to arouse the emotion necessary to enhance use of the teachable moment provided by cardiac risk factor assessment. Our focus group participants' reactions to 3 risk communication strategies indicate they preferred a method that engaged their attention in a manner to which they could personally relate. The personal element, therefore, may be critical for alerting patients to how they, as individuals, can be affected by CVD risk and may be important for motivating patients to talk with their physicians and change behaviors to improve their cholesterol levels. A cardiovascular risk-adjusted age strategy uses a calculation based on probability estimates and converts it into a concept using age that participants found meaningful, easy to understand, and memorable. Some, however, were concerned that the emotion aroused by the risk-adjusted age strategy may be frightening, indicating that such an approach must be accompanied by clear messages regarding how individuals can work with their physicians to reduce their CVD risk. The strategy avoids vaguely elastic terminology, such as "likely," "rare," and "chance of occurrence," and it may help overcome the barriers of interpretation of numbers for patient-physician communication. ${ }^{24,27,46,47}$ Our participants' interest in the cardiovascular risk-adjusted age strategy is consistent with other observations that although patients often desire more information than they are getting from their clinicians, their wish is not for raw data, complicated medical explanations, or population estimates. Rather, they seek personally meaningful information that may prove helpful as they make their health care and lifestyle decisions. ${ }^{27}$ If physicians can achieve this essential initial step of truly engaging patients with the notion of their own cholesterol-related CVD risk, then patients may be better prepared to understand and internalize the elements of traditional cholesterol education that our participants found to be confusing or irrelevant. The findings from this research, then, pose a question for debate concerning the type and amount of detailed information most appropriate for motivating behavior change. This study suggests a way forward and may help clarify our cholesterol education efforts.

To read or post commentaries in response to this article, see it online at http://www.annfammed.org/cgi/current/full/4/3/205.

Key words: Methodological study; qualitative research; hypercholesterolemia; cardiovascular disease; medical decision-making; informatics; communication; patient education; health promotion;
Submitted March 25, 2005; submitted revised November 15, 2005; accepted November 28, 2005.

Portions of the article content were presented at the North American Primary Care Research Group (NAPCRG) conference in Banff, Canada on October 27, 2003; at the Memorial Hospital of Rhode Island Annual Kenney Research Day on March 5, 2004; and at the Brown Public Health Research Day on April 5, 2005.

Funding support: This research was supported by the National Institutes of Health, Bethesda, Maryland; grant \# NIH-NHLBI R01 HL70804.

Acknowledgments: We would like to acknowledge the assistance of Jerome McMurray and Jennifer Vancura with focus group logistics and data management.

\section{References}

1. Heart Disease and Stroke Statistics-2004 Update. Dallas, TX: American Heart Association; 2003.

2. Report of the National Cholesterol Education Program Expert Panel on Detection, Evaluation, and Treatment of High Blood Cholesterol in Adults. The Expert Panel. Arch Intern Med. 1988; 148:36-69.

3. Summary of the second report of the National Cholesterol Education Program (NCEP) Expert Panel on Detection, Evaluation, and Treatment of High Blood Cholesterol in Adults (Adult Treatment Panel II). JAMA. 1993;269:3015-3023.

4. Executive Summary of The Third Report of The National Cholesterol Education Program (NCEP) Expert Panel on Detection, Evaluation, and Treatment of High Blood Cholesterol In Adults (Adult Treatment Panel III). JAMA. 2001;285:2486-2497.

5. Third Report of the National Cholesterol Education Program (NCEP) Expert Panel on Detection, Evaluation, and Treatment of High Blood Cholesterol in Adults (Adult Treatment Panel III) final report. Circulation. 2002;106:3143-3421.

6. National Heart, Lung, and Blood Institute, National Institutes of Health. National Cholesterol Education Month Kit - Know Your Cholesterol Numbers, Know Your Risk. Available at: http://hin.nhlbi. nih.gov/cholmonth/index.htm.

7. Schucker B, Bailey K, Heimbach JT, et al. Change in public perspective on cholesterol and heart disease. Results from two national surveys. JAMA. 1987;258:3527-3531.

8. Schucker B, Wittes JT, Santanello NC, et al. Change in cholesterol awareness and action. Results from national physician and public surveys. Arch Intern Med. 1991;151:666-673.

9. Cleeman JI, Lenfant C. The National Cholesterol Education Program: progress and prospects. JAMA. 1998;280:2099-2104.

10. Ford ES, Mokdad AH, Giles WH, Mensah GA. Serum total cholesterol concentrations and awareness, treatment, and control of hypercholesterolemia among US adults: findings from the National Health and Nutrition Examination Survey, 1999 to 2000. Circulation. 2003;107:2185-2189.

11. Carroll C, Naylor E, Marsden P, Dornan T. How do people with Type 2 diabetes perceive and respond to cardiovascular risk? Diabet Med. 2003;20:355-360.

12. Yoon SS, Byles J. Perceptions of stroke in the general public and patients with stroke: a qualitative study. BMJ. 2002;324:1065-1068.

13. Frijling BD, Lobo CM, Keus IM, et al. Perceptions of cardiovascular risk among patients with hypertension or diabetes. Patient Educ Couns. 2004;52:47-53.

14. Durack-Bown I, Giral P, d'Ivernois JF, et al. Patients' and physicians' perceptions and experience of hypercholesterolaemia: a qualitative study. Br J Gen Pract. 2003;53:851-857. 
15. Tolmie EP, Lindsay GM, Kerr SM, et al. Patients' perspectives on statin therapy for treatment of hypercholesterolaemia: a qualitative study. Eur J Cardiovasc Nurs. 2003;2:141-149.

16. Ali NS. Prediction of coronary heart disease preventive behaviors in women: a test of the health belief model. Women Health 2002:35:83-96.

17. Meischke $H$, Sellers DE, Robbins $M L$, et al. Factors that influence personal perceptions of the risk of an acute myocardial infarction. Behav Med. 2000;26:4-13.

18. Hsieh C, Novielli KD, Diamond JJ, Cheruva D. Health beliefs and attitudes toward the prevention of osteoporosis in older women. Menopause. 2001;8:372-376

19. Cavill N, Bauman A. Changing the way people think about healthenhancing physical activity: do mass media campaigns have a role? J Sports Sci. 2004;22:771-790.

20. Gans KM, Assmann SF, Sallar A, Lasater TM. Knowledge of cardiovascular disease prevention: an analysis from two New England communities. Prev Med. 1999;29:229-237.

21. Kirsch IS, Jungeblat A, Jenkins L, Kolstad A. Adult Literacy in America: A First Look at the Results of the National Adult Literacy Survey. Washington, DC: National Center for Educational Statistics, US Department of Education; 1993.

22. Nielsen-Bohlman L, Panzer A, Kindig D, eds. Health Literacy: A Prescription to End Confusion. Washington, DC: National Academies Press; 2004.

23. Schillinger D, Bindman A, Wang F, Stewart A, Piette J. Functional health literacy and the quality of physician-patient communication among diabetes patients. Patient Educ Couns. 2004;52:315-323.

24. Lipkus IM, Samsa G, Rimer BK. General performance on a numeracy scale among highly educated samples. Med Decis Making. $2001 ; 21: 37-44$

25. Woloshin S, Schwartz LM, Moncur M, Gabriel S, Tosteson AN. Assessing values for health: numeracy matters. Med Decis Making. 2001;21:382-390.

26. Lipkus IM, Hollands JG. The visual communication of risk. J Nat Cancer Inst Monogr. 1999:149-163.

27. Edwards A, Elwyn G, Mulley A. Explaining risks: turning numerical data into meaningful pictures. BMJ. 2002;324:827-830.

28. Woloshin S, Schwartz LM, Welch HG. Risk charts: putting cancer in context. J Natl Cancer Inst. 2002;94:799-804.

29. Edwards A. Communicating risks through analogies. BMJ. 2003;327:749.

30. Lee SY, Arozullah AM, Cho YI. Health literacy, social support, and health: a research agenda. Soc Sci Med. 2004;58:1309-1321.

31. Williams MV, Davis T, Parker RM, Weiss BD. The role of health literacy in patient-physician communication. Fam Med. 2002;34:383-389.
32. Morgan D. Focus Groups as Qualitative Research. Newbury Park, Calif: Sage Publications; 1988.

33. Brown JB. The Use of Focus Groups in Clinical Research. In: Crabtree B, Miller W, eds. Doing Qualitative Research. 2nd ed. Thousand Oaks, Calif: Sage Publications; 1999:109-124.

34. Calderon JL, Baker RS, Wolf KE. Focus groups: a qualitative method complementing quantitative research for studying culturally diverse groups. Educ Health (Abingdon). 2000;13:91-95.

35. Anderson KM, Wilson PW, Odell PM, Kannel WB. An updated coronary risk profile. A statement for health professionals. Circulation. 1991;83:356-362.

36. Grundy SM, D'Agostino Sr RB, Mosca L, et al. Cardiovascular risk assessment based on US cohort studies: findings from a National Heart, Lung, and Blood institute workshop. Circulation. 2001;104:491-496.

37. Borkan J. Immersion/crystallization. In: Crabtree B, Miller W, eds. Doing Qualitative Research. $2^{\text {nd }}$ ed. Thousand Oaks, Calif: Sage Publications; 1999:179-194.

38. QSR NVivo. Version Melbourne, Australia: QSR International Pty Ltd; 2000.

39. Public Awareness and Behavior Regarding Preventive Health Screenings. Princeton, NJ: The Gallup Organization and the College of American Pathologists; 2004. Available at: http://www.cap.org/ apps/docs/online_media_kit/gallup_report.pdf.

40. Highlights from the College of American Pathologists' 2003 Preventive Testing Gallup Study. Princeton, NJ: The Gallup Organization; 2004.

41. Whiteside C, Robbins JA. Cholesterol knowledge and practices among patients compared with physician management in a university primary care setting. Prev Med. 1989;18:526-531.

42. Glanz K, Brekke M, Hoffman E, et al. Patient reactions to nutrition education for cholesterol reduction. Am J Prev Med. 1990;6:311-317.

43. Davison C, Frankel S, Smith GD. The limits of lifestyle: re-assessing 'fatalism' in the popular culture of illness prevention. Soc Sci Med. 1992;34:675-685.

44. Murray SA, Manktelow K, Clifford C. The interplay between social and cultural context and perceptions of cardiovascular disease. I Adv Nurs. 2000;32:1224-1233.

45. Farrell MH, Murphy MA, Schneider CE. How underlying patient beliefs can affect physician-patient communication about prostatespecific antigen testing. Eff Clin Pract. 2002;5:120-129.

46. Rothman AJ, Kiviniemi MT. Treating people with information: an analysis and review of approaches to communicating health risk information. J Natl Cancer Inst Monogr. 1999:44-51.

47. Hoffrage U, Lindsey S, Hertwig R, Gigerenzer G. Medicine. Communicating statistical information. Science. 2000;290:2261-2262. 